\title{
Interprofessional Peer Teaching: Assistive Device Training and Medications Impacting Safe Ambulation
}

\author{
Niamh M. Tunney \\ Mercer University, tunney_nm@mercer.edu \\ Melissa Chesson \\ Mercer University, chesson_mm@mercer.edu \\ Gina J. Ryan \\ Mercer University, ryan_gj@mercer.edu
}

Follow this and additional works at: https://nsuworks.nova.edu/ijahsp

Part of the Pharmacy and Pharmaceutical Sciences Commons, and the Rehabilitation and Therapy Commons

This Manuscript has supplementary content. View the full record on NSUWorks here: https://nsuworks.nova.edu/ijahsp/vol18/iss2/5

\section{Recommended Citation}

Tunney NM, Chesson M, Ryan GJ. Interprofessional Peer Teaching: Assistive Device Training and Medications Impacting Safe Ambulation. The Internet Journal of Allied Health Sciences and Practice. 2020 Jan 01;18(2), Article 5.

This Manuscript is brought to you for free and open access by the College of Health Care Sciences at NSUWorks. It has been accepted for inclusion in Internet Journal of Allied Health Sciences and Practice by an authorized editor of NSUWorks. For more information, please contact nsuworks@nova.edu. 


\title{
Interprofessional Peer Teaching: Assistive Device Training and Medications Impacting Safe Ambulation
}

\begin{abstract}
ABSTRACT

Purpose: An interprofessional peer teaching activity was designed and implemented to provide students with an opportunity to practice interprofessional education collaborative (IPEC) competencies while improving student knowledge of assistive devices for gait and medications impacting safe ambulation. Method: During the activity, second year physical therapy students instructed third year pharmacy students in the accurate fit and counseling for use of canes, crutches, and walkers. Pharmacy students then demonstrated these skills and were checked off on their ability to accurately fit and instruct consumers on basic gait patterns. The pharmacy students in turn educated the physical therapy students about medications that impact safe ambulation and gait training. The activity was designed to meet the interprofessional competencies of roles and responsibilities, interprofessional communication, teams and teamwork, in addition to specific course objectives. Students completed a 15 -item pre- and postknowledge assessment and a perceptions survey to evaluate the effectiveness of the peer teaching activity. Results: Significant improvements in knowledge and performance were demonstrated following participation in the activity, and students reported positive perceptions of the activity and its impact on their learning about assistive devices and medications reviewed during the session. Our results indicate that physical therapy and pharmacy students can effectively teach each other and learn about assistive devices and medications impacting safe ambulation through an interprofessional peer teaching activity. Conclusion: Peer teaching across disciplines can help prepare students to communicate and collaborate with other healthcare providers.
\end{abstract}

\section{Author Bio(s)}

Niamh Tunney, PT, DPT, MS, Clinical Associate Professor of Physical Therapy, Mercer University College of Health Professions, Mercer Health Sciences Center, Atlanta, Georgia

Melissa M. Chesson, PharmD, BCPS, Clinical Associate Professor of Pharmacy Practice, Mercer University College of Pharmacy, Mercer Health Sciences Center, Atlanta, Georgia

Gina Ryan,PharmD, CDE, Clinical Professor and Associate Dean for Strategic Initiatives, Mercer University College of Pharmacy, Mercer Health Sciences Center, Atlanta, Georgia 


\title{
IIIAHSP
}

\section{The Internet Journal of Allied Health Sciences and Practice \\ Dedicated to allied health professional practice and education}

Vol. 18 No. 1 ISSN 1540-580X

\section{Interprofessional Peer Teaching: Assistive Device Training and Medications Impacting Safe Ambulation}

\author{
Niamh M. Tunney \\ Melissa Chesson \\ Gina J. Ryan \\ Mercer University \\ United States
}

\begin{abstract}
Purpose: An interprofessional peer teaching activity was designed and implemented to provide students with an opportunity to practice interprofessional education collaborative (IPEC) competencies while improving student knowledge of assistive devices for gait and medications impacting safe ambulation. Method: During the activity, second year physical therapy students instructed third year pharmacy students in the accurate fit and counseling for use of canes, crutches, and walkers. Pharmacy students then demonstrated these skills and were checked off on their ability to accurately fit and instruct consumers on basic gait patterns. The pharmacy students in turn educated the physical therapy students about medications that impact safe ambulation and gait training. The activity was designed to meet the interprofessional competencies of roles and responsibilities, interprofessional communication, teams and teamwork, in addition to specific course objectives. Students completed a 15 -item pre- and postknowledge assessment and a perceptions survey to evaluate the effectiveness of the peer teaching activity. Results: Significant improvements in knowledge and performance were demonstrated following participation in the activity, and students reported positive perceptions of the activity and its impact on their learning about assistive devices and medications reviewed during the session. Our results indicate that physical therapy and pharmacy students can effectively teach each other and learn about assistive devices and medications impacting safe ambulation through an interprofessional peer teaching activity. Conclusion: Peer teaching across disciplines can help prepare students to communicate and collaborate with other healthcare providers.
\end{abstract}

Keywords: interprofessional education, physical therapy, pharmacy 


\section{BACKGROUND}

The basic premise of interprofessional education (IPE) is that patient care will improve when health care professionals begin to work together collaboratively, and that the skills needed for effective interprofessional collaboration should be developed during professional education and carried forward into practice. ${ }^{1}$ There is evidence to indicate that effective interprofessional education enables effective collaborative practice and positive attitudes towards collaborative practice. ${ }^{3}$ Additionally, IPE has been supported in systematic reviews as an effective strategy for producing better patient outcomes. ${ }^{4,5}$ In recognition of the efficacy of IPE, the accrediting agencies of many healthcare disciplines, including pharmacy and physical therapy, already require IPE experiences to be provided in the professional curriculum ${ }^{6,7}$ It is therefore incumbent upon health professional education programs to provide IPE experiences that are meaningful and translational. Interprofessional education has been described as those occasions when students from two or more professions learn with, from, and about each other to improve collaboration and the quality of care. ${ }^{8}$ This broad definition has allowed for a great diversity of educational approaches to be employed in interprofessional education. ${ }^{9}$ Approaches described in the literature include didactic courses, interdisciplinary team rounds using real patients or paper cases, care teams acting as health mentors in the community, use of standardized patients, clinical rotations and service learning, emergency drills, and peer-to-peer teaching. ${ }^{9,10,11}$ The range of curricular topics for IPE is also very broad and includes health assessment, patient safety, communication, contemporary healthcare systems, cultural awareness and international health, emergency preparedness, professional ethics, special patient populations, and conflict negotiation. ${ }^{1}$

Burgess concluded that teaching is an important skill that needs development in all graduate healthcare programs and that it should occur within and across disciplines. ${ }^{12}$ This prompted faculty in pharmacy and physical therapy programs at this university to explore development of a peer-to-peer teaching activity that would serve to develop teaching skills while exploring interprofessional collaboration and communication. Peer teaching has been recognized as a viable and effective option for interprofessional education. First and second-year medical and pharmacy students participated in small-group problem-based learning IPE seminars led by second-year medical students. Data showed significantly higher perception of professional cooperation among those who attended IPE compared to those who did not. ${ }^{13}$ In a study where physical therapy and occupational therapy students taught rehabilitation assessments and interventions to medical students as part of a connective tissue unit, participants perceived the experience as valuable, satisfying, and relevant, and reported enhanced confidence and professional role identity. ${ }^{14}$ A study examining the efficacy of peer teaching provided by PT students for pharmacy students also demonstrated that interprofessional learning proved successful. ${ }^{15}$ Shields et al described student satisfaction with a peer-to-peer interprofessional education activity where PT students presented a musculoskeletal assessment of the upper quarter to medical students, and the disciplines experienced the interaction of their education and practice. Both groups provided positive feedback about the experience and reported a willingness for additional similar interactions. ${ }^{16}$ Researchers used peer-to-peer teaching to foster interprofessional communication and collaboration when pharmacy students educated nursing and medical students/residents about Medicare Part D. Analysis of both qualitative and quantitative data revealed that peer-to-peer education was an effective means of providing content education for multiple disciplines while promoting interprofessional collaboration. ${ }^{17}$ When faculty in the College of Pharmacy and Department of Physical Therapy identified an area of curricular overlap related to patient safety, they saw the opportunity for interprofessional collaboration that would ultimately increase safety for those consumers interacting with either or both professions and provided a meaningful context for addressing interprofessional competencies. They created and implemented an IPE activity that involved reciprocal peer-to-peer teaching, and the curricular topic was patient safety when ambulating with assistive devices.

It is estimated that there are approximately seven million Americans who use assistive devices to assist with safe ambulation and to decrease the risk of falls. ${ }^{18}$ The most commonly used assistive devices include canes, walkers, and crutches. ${ }^{18}$ In addition to medical conditions that involve impairments necessitating use of an assistive device, medication side effects can contribute to gait instability and increased fall risk. ${ }^{19}$ Physical therapists need to be familiar with the medications that have these side effects and be able to recognize the impact of medications on gait function. Traditionally, assistive device training has been provided by PTs, but not all patients see a PT to have an assistive device prescribed and fit appropriately and to receive gait training. Individuals in the community can decide independently to purchase an assistive device providing pharmacists with the unique opportunity to counsel them in the use of these devices and to provide proper fitting when appropriate. Therefore, pharmacy students should receive the training to do so effectively. It is also essential that pharmacy students recognize when it is more appropriate to refer to a physical therapist for assistive device training because of the complexity of the gait needs, the level of disability involved, or the presence of weight-bearing restrictions or gait precautions. This interprofessional reciprocal peer teaching activity was developed and implemented so that students from both disciplines could learn the skills or knowledge needed to play their part in facilitating safe ambulation with devices while learning about each other's respective roles and responsibilities and the importance of effective communication and collaborative care. 
In addition to interprofessional education collaborative competencies, students from both disciplines had specific course objectives relating to knowledge and performance that could be met by this peer-to-peer teaching activity. Specific PT program objectives included 1) to demonstrate competence in the education of others using culturally appropriate and age-appropriate teaching methods; 2) to provide effective instruction that is current and appropriate regarding indications for physical therapy referral; and 3 ) to recognize the impact of medications on patient performance and outcomes. Specific program objectives for the pharmacy students included 1) to demonstrate verbal and written communication skills in the presentation of drug therapies and patient counselling; 2) describe and/or to demonstrate appropriate use of durable medical equipment; and 3) to describe the role of other healthcare professionals in the health care team. While engaged in the reciprocal peer teaching activity, students from each of the professions were able to explore IPE core competencies, specifically roles and responsibilities and interprofessional communication, and to experience the benefit of interprofessional collaboration to ensure patient safety. Specific IPE goals identified for both groups were 1) to communicate and collaborate with a future healthcare partner (CC2); 2) to identify the complementary roles and responsibilities of physical therapists and pharmacists in assistive device training and management of medications related to safe ambulation (RR9); 3 ) to foster a culture of mutual respect between physical therapists and pharmacists (RR7); and 4) share accountability with other professions, patients, and communities for outcomes relevant to prevention and health care (TT7). ${ }^{20}$

The purpose of this paper is to present the development and implementation of a reciprocal peer teaching IPE activity, to evaluate whether students can learn overlapping content and skills through a reciprocal peer teaching IPE event, and to characterize student perceptions of the IPE activity.

\section{METHODS}

Study Design

A pre-test post-test design was used.

\section{Participants}

The activity was implemented for two consecutive cohorts of students. Doctor of Physical Therapy students $(\mathrm{N}=74)$ and Doctor of Pharmacy students ( $N=321)$ at one university participated in the activity. The physical therapy (PT) students were in the fourth semester of an eight-semester doctor of physical therapy program and the pharmacy students were at the start of their third professional year within a four-year doctor of pharmacy program. Participation in the IPE activity was required for students in both programs and occurred within courses for which IPE was considered the optimum strategy for meeting course content objectives.

\section{Procedures}

The IPE activity was offered during the fall semester of two consecutive years. The Institutional Review Board at the University approved the study, and students provided informed consent for investigators to report the data collected. This work was supported by a University Interprofessional Education Development Grant. Two faculty (one from each program) were involved in planning and implementation of the activity and facilitation of groups throughout the event. Prior to participation in the activity, PT students successfully completed a competency assessment of the skills required for instruction in the use of assistive devices, and pharmacy students' prior coursework included the medications reviewed during the activity ensuring that both groups had the background needed to provide effective instruction. Approximately one month prior to the activity, pharmacy students were provided with instructions to create a two-page handout describing key points related to medications commonly impacting safe ambulation. These medications were selected by the course faculty. Students were instructed to include information on the indications, mechanism of action, specific impact(s) on safe ambulation (i.e. dizziness, drowsiness, orthostatic hypotension, muscle weakness, visual disturbances), and clinical pearls of the selected medications (Table 1).

Pharmacy students were required to submit their handout prior to the session for faculty review. After faculty approval, students were instructed to bring handouts to the activity for all group members. Physical therapy students provided an abbreviated version of handouts they had received when learning assistive device training procedures earlier in the curriculum.

The activity occurred in the university gymnasium, which had been set up specifically for the session. Students were randomly assigned to 36 groups consisting of four or five pharmacy students and one PT student. The activity occurred in 2 rounds lasting 1.5 hours each with 18 groups participating per round. Each group was assigned to a station that had three standard folding chairs, a rolling walker, a pair of axillary crutches, a quad cane, and a straight cane. 
Table 1: Medications Impacting Safe Ambulation Handout Template

\begin{tabular}{|l|l|l|l|l|}
\hline \multicolumn{1}{|c|}{$\begin{array}{l}\text { Medication Class/Names } \\
\text { (selected medications) }\end{array}$} & Indications & $\begin{array}{c}\text { Impact on Safe Ambulation } \\
\text { (i.e. dizziness, drowsiness, } \\
\text { orthostatic hypotension, } \\
\text { muscle weakness, or visual } \\
\text { disturbance) }\end{array}$ & $\begin{array}{c}\text { Clinical } \\
\text { Pearls }\end{array}$ \\
\hline Alcohol & & & & \\
\hline Hydrochlorothiazide (HCTZ) & & & & \\
\hline Furosemide) & & & & \\
\hline Doxazosin & & & & \\
\hline Nitroglycerin & & & & \\
\hline Digoxin & & & & \\
\hline Statins (i.e. simvastatin, atorvastatin) & & & \\
\hline $\begin{array}{l}\text { Anti-cholinergics (i.e.oxybutynin, } \\
\text { tolterodine) }\end{array}$ & & & & \\
\hline Diphenhydramine & & & & \\
\hline Gabapentin & & & & \\
\hline Haloperidol & & & & \\
\hline $\begin{array}{l}\text { Benzodiazepines (i.e. alprazolam, } \\
\text { lorazepam) }\end{array}$ & & & & \\
\hline Antidepressants (i.e. fluoxetine, trazodone) & & & & \\
\hline Amitriptyline & & & & \\
\hline $\begin{array}{l}\text { Narcotics (i.e. codeine, oxycodone } \\
\text { morphine) }\end{array}$ & & & & \\
\hline $\begin{array}{l}\text { Muscle Relaxants (i.e. baclofen, } \\
\text { carisoprodol) }\end{array}$ & & & & \\
\hline Eye drops & & & & \\
\hline
\end{tabular}

At the start of the session, faculty provided students with instructions to work at their own pace to provide peer teaching regarding assistive devices and selected medications. Physical therapy students instructed pharmacy students in the accurate fit of canes, walkers, and crutches, safe transition from sit to stand with each device, and 2 and 3-point gait patterns without weight-bearing restrictions. Physical therapy students explained and demonstrated the psychomotor skills involved in each of the procedures and provided each pharmacy student with an opportunity for supervised practice of each fitting procedure and each gait pattern. The PT students used simple case scenarios to provide context for the assistive device selection. Following instruction and practice, the PT students confirmed pharmacy students' competence in these skills using a check-off form (Table 2) and provided the pharmacy students with a summary handout of the activities practiced. Indications for referral to PT were presented to the group verbally and were also included in the handout.

Table 2: Assistive device demonstration check-off form

\begin{tabular}{|c|c|c|c|c|c|c|c|}
\hline \multirow[t]{4}{*}{ Student Name } & \multicolumn{2}{|c|}{ Crutches } & \multicolumn{2}{|r|}{ Canes } & \multicolumn{2}{|c|}{ Walkers } & Comments \\
\hline & & Gait pattern & & Gait pattern & & Gait pattern & \\
\hline & & Fit & $\square$ & Fit & $\square$ & Fit & \\
\hline & & Counseling & & Counseling & & Counseling & \\
\hline
\end{tabular}

Pharmacy students then instructed PT students about medications that impact safe ambulation. To ensure that all the pharmacy students provided peer teaching, each pharmacy student in the group presented three to four medications/medication classes from the group's prepared medication handout. Faculty facilitated group discussions when groups appeared to be off-task, inaccurate information was being shared, or when a question arose. This session highlighted the inter-dependence of the professions in this area of practice, the roles each contribute to the safety and well-being of patients' dependent on assistive devices and provided an opportunity to practice interprofessional communication. 


\section{Assessment}

Achievement of the course specific learning objectives was assessed using a 15 -item multiple choice pre and post-test created by the course faculty and administered by survey (Appendix). Students completed the pre-test in class approximately one week prior to the session. The test focused on the key points regarding correct use of assistive devices, PT referrals, and medications impacting safe ambulation. Questions 1-8 focused on content covered by the PT students during the activity and questions 9-15 pertained to pharmacy student content, and students answered all questions regardless of discipline. Students completed the same assessment as a post-test one week after participation in the activity.

Competence in fitting of the devices and in accurate demonstration of, and counseling for, a variety of gait patterns with the devices was assessed using a simple check-off form (Table 2). Each pharmacy student in the group was checked off individually by the instructing PT student.

Students were also asked to complete a survey evaluating the session, with questions specifically targeting both the IPE objectives and profession-specific objectives for the activity (Tables3,4,5). Physical therapy students completed an 11-item survey and pharmacy students completed a 13-item survey. The first eight questions in the survey were answered by students from both programs and the remaining questions were profession-specific. Students rated their responses to survey questions using a 5item Likert scale ( $1=$ strongly disagree, 2 = disagree, $3=$ neutral, $4=$ agree, $5=$ strongly agree). The perceptions survey was completed at the same time as the knowledge post-assessment.

\section{Data Analysis}

Descriptive statistics were used to examine pre-test and post-test scores of both groups, as well as to characterize perceptions data. Pre-test and post-test percentage scores were compared utilizing paired student's t-tests for continuous variables to evaluate changes in student knowledge.

\section{RESULTS}

A total of 67 PT students and 254 PharmD students completed the pre- and post-tests /knowledge assessments (81.3\% response rate) over the two years of the activity. Overall, knowledge test scores for the combined groups improved from $56.9 \%$ at baseline to $69.9 \%$ ( $p<0.01$ ) following activity completion (Figure 1). Students improved their knowledge of PT-focused questions by $15.9 \%$ and pharmacy-focused questions by $9.7 \%$ ( $p<0.01$ for combined groups). Physical therapy students' knowledge test scores improved by $5.4 \%$ and pharmacy students' scores improved by $15.1 \%$ following activity completion ( $p<0.01$ for combined groups). Physical therapy students scored higher on the pre- and post-tests than pharmacy students. Each profession improved their test scores of both their own profession and the other profession's focused questions. Both groups of students were more knowledgeable when answering their own profession-focused questions compared to the other profession's questions. Pharmacy students' knowledge of PT-focused questions improved the most of all comparisons (19\%; $p=0.01$ ).

Overall, students' perceptions of the IPE activity were positive (Table 3). The majority of students (98.5\%) agreed or strongly agreed that their professional expertise was respected during the session. Ninety-five percent of students felt they have a greater understanding of the roles and responsibilities of the PT in assistive device prescription and gait training. Most students (96.9\%) also agreed or strongly agreed that the activity improved their understanding of the roles and responsibilities of the pharmacist in the provision of assistive devices. The activity also promoted collaboration between disciplines and the activity afforded students the opportunity to practice communicating with a future healthcare partner $(97.5 \%$ and $96.9 \%$ respectively of students agreed or strongly agreed). As an overall recommendation, $95.3 \%$ of students agreed or strongly agreed that this was a beneficial activity and should be included in IPE programming for The University.

Students also evaluated the activities' ability to meet profession-specific outcomes. Over $90 \%$ of PT students either agreed or strongly agreed they were prepared to provide instruction to pharmacy students on the use of assistive devices and that the activity helped them to develop competence in assistive device education of others. While the majority of PT students responded positively to the survey statement evaluating how well the activity helped the PT student to recognize medications impairing safe ambulation, $10.5 \%$ of PT students disagreed or strongly disagreed with the statement (Table 4). 
A. All Students

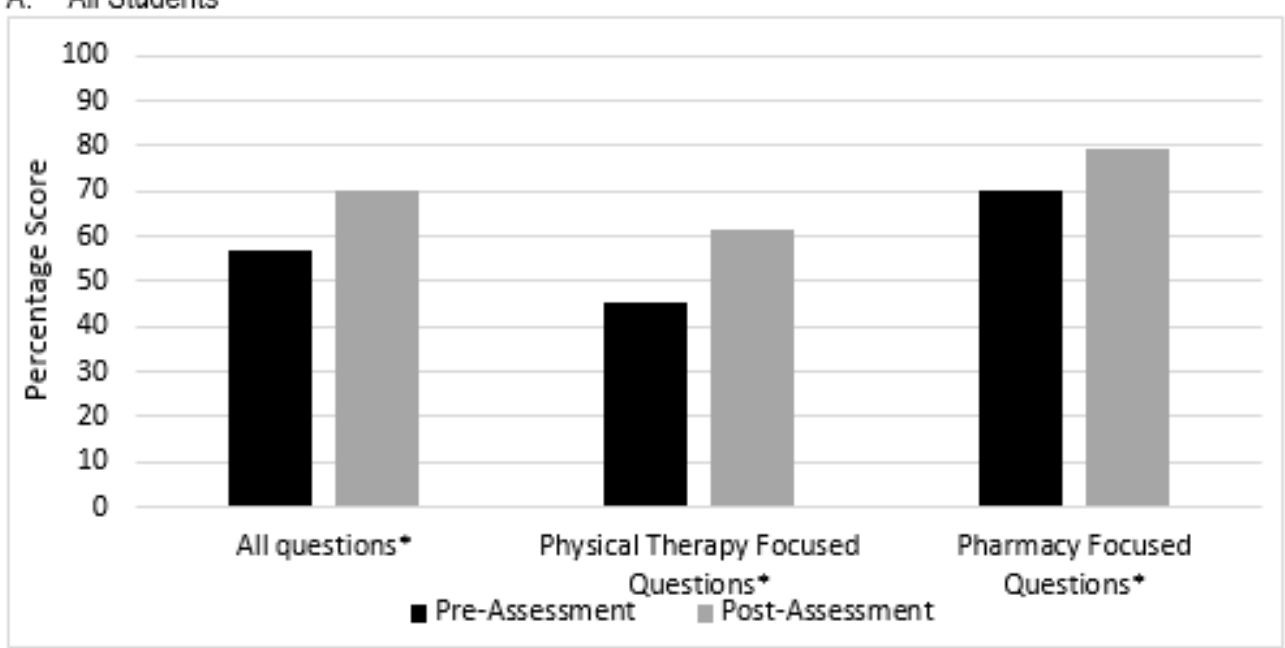

B. Physical Therapy Students

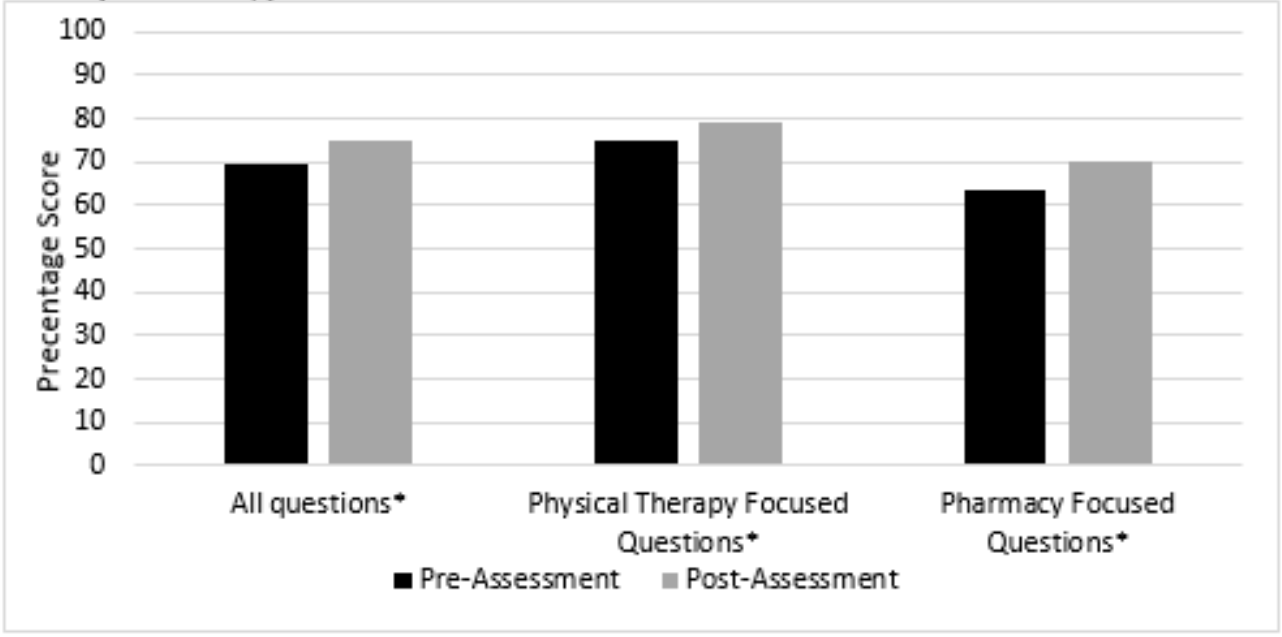

C. Pharmacy Students

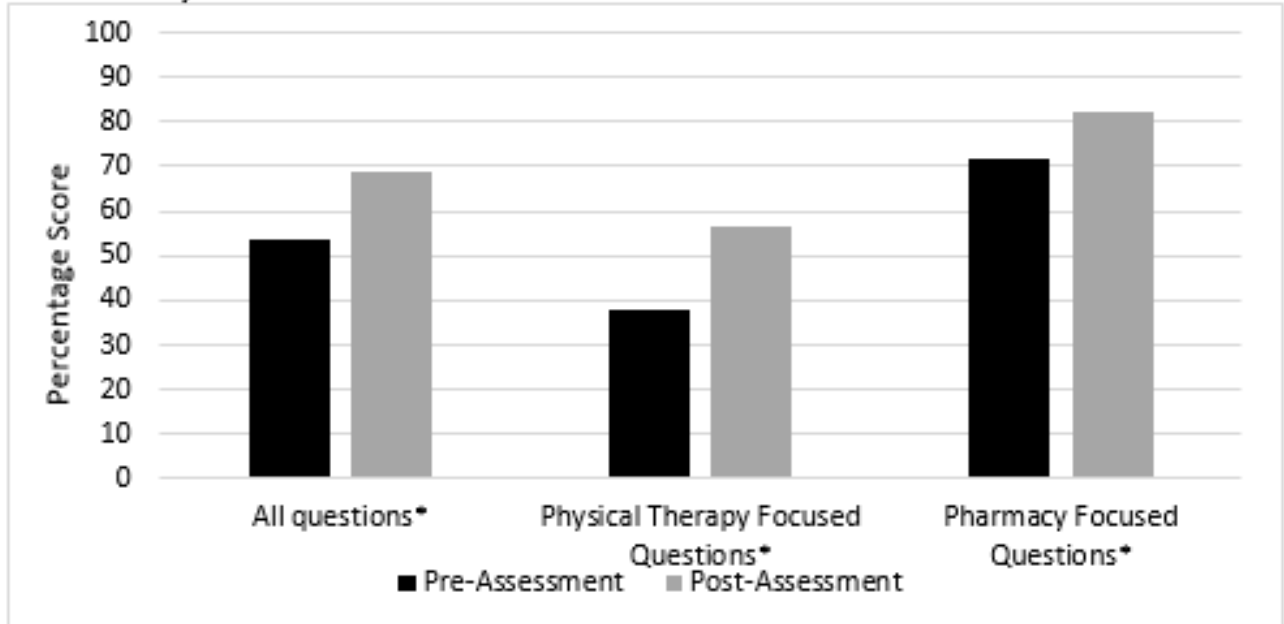

Figure 1. Comparison of Knowledge Assessment Scores (out of 100\%); $p<0.05$ for comparison 
Table 3. Physical Therapy and Pharmacy Students' Responses to IPE Specific Perceptions Survey Questions ( $N=321$ )

\begin{tabular}{|l|l|l|l|l|l|}
\hline Question & $\begin{array}{c}\text { Strongly } \\
\text { Disagree }\end{array}$ & Disagree & Neutral & Agree & $\begin{array}{c}\text { Strongly } \\
\text { Agree }\end{array}$ \\
\hline $\begin{array}{l}\text { I felt that my professional expertise was respected by the other } \\
\text { profession. }\end{array}$ & $0.9 \%$ & $0 \%$ & $0.6 \%$ & $17.8 \%$ & $80.7 \%$ \\
\hline The facilities were adequate for practicing the skills presented. & $0.9 \%$ & $0 \%$ & $3.4 \%$ & $23.7 \%$ & $72.0 \%$ \\
\hline I had adequate equipment to provide the instruction. & $0.9 \%$ & $0.3 \%$ & $3.4 \%$ & $23.1 \%$ & $72.3 \%$ \\
\hline $\begin{array}{l}\text { I have a greater understanding of the roles and responsibilities } \\
\text { of physical therapists in assistive device prescription and gait } \\
\text { training. }\end{array}$ & $1.2 \%$ & $0 \%$ & $5.0 \%$ & $18.7 \%$ & $75.1 \%$ \\
\hline $\begin{array}{l}\text { I have a greater understanding of the roles and responsibilities } \\
\text { of pharmacists in the provision of assistive devices. }\end{array}$ & $1.2 \%$ & $0 \%$ & $1.9 \%$ & $34 \%$ & $62.9 \%$ \\
\hline $\begin{array}{l}\text { The session promoted collaboration between physical } \\
\text { therapists and pharmacists. }\end{array}$ & $0.6 \%$ & $0.3 \%$ & $1.6 \%$ & $16.5 \%$ & $81.0 \%$ \\
\hline $\begin{array}{l}\text { This activity afforded me the opportunity to practice } \\
\text { communicating with a future healthcare partner. }\end{array}$ & $0.9 \%$ & $0.3 \%$ & $1.9 \%$ & $17.8 \%$ & $79.1 \%$ \\
\hline $\begin{array}{l}\text { This would be a beneficial activity to include in the IPE } \\
\text { programming on campus. }\end{array}$ & $1.6 \%$ & $0.6 \%$ & $2.5 \%$ & $19.3 \%$ & $76.0 \%$ \\
\hline
\end{tabular}

Table 4. Physical Therapy students' responses to profession-specific perceptions survey questions ( $N=67)$

\begin{tabular}{|l|l|l|l|l|l|}
\hline Question & $\begin{array}{c}\text { Strongly } \\
\text { Disagree }\end{array}$ & Disagree & Neutral & Agree & $\begin{array}{c}\text { Strongly } \\
\text { Agree }\end{array}$ \\
\hline $\begin{array}{l}\text { This activity helped me to develop competence in assistive } \\
\text { device education of others using culturally-appropriate and } \\
\text { age-appropriate teaching methods. }\end{array}$ & $1.5 \%$ & $0 \%$ & $6.0 \%$ & $28.4 \%$ & $64.2 \%$ \\
\hline $\begin{array}{l}\text { I felt well prepared to provide instruction in the skills required } \\
\text { for the session. }\end{array}$ & $1.5 \%$ & $0 \%$ & $0 \%$ & $28.4 \%$ & $70.1 \%$ \\
\hline $\begin{array}{l}\text { This activity helped me to recognize medications that can } \\
\text { cause impairments in safe ambulation and alterations in gait } \\
\text { patterns. }\end{array}$ & $3.0 \%$ & $7.5 \%$ & $20.9 \%$ & $43.3 \%$ & $25.4 \%$ \\
\hline
\end{tabular}

Similar to the PT students, most pharmacy students (93.3\%) agreed or strongly agreed that the activity helped them to develop competence in medication education of others. Pharmacy students also reported positive perceptions of the activity relating to their ability to demonstrate the appropriate use of assistive devices, identify counseling points for assistive devices dispensed in the pharmacy, and when to refer a patient to PT for assistive device training (Table 5).

Table 5. Pharmacy students' responses to profession-specific perceptions survey questions ( $N=254)$

\begin{tabular}{|l|l|l|l|l|l|}
\hline Question & $\begin{array}{c}\text { Strongly } \\
\text { Disagree }\end{array}$ & Disagree & Neutral & Agree & $\begin{array}{c}\text { Strongly } \\
\text { Agree }\end{array}$ \\
\hline $\begin{array}{l}\text { This activity helped me to develop competence in medication } \\
\text { education of others using culturally-appropriate and age- } \\
\text { appropriate teaching methods. }\end{array}$ & $0.9 \%$ & $0 \%$ & $5.9 \%$ & $26.8 \%$ & $66.5 \%$ \\
\hline $\begin{array}{l}\text { I felt well prepared to provide instruction in the medications } \\
\text { discussed during the session. }\end{array}$ & $0.9 \%$ & $0 \%$ & $2.8 \%$ & $26.4 \%$ & $70.1 \%$ \\
\hline $\begin{array}{l}\text { This activity helped me to know how to demonstrate } \\
\text { appropriate use of assistive devices dispensed in the } \\
\text { pharmacy. }\end{array}$ & $1.2 \%$ & $0 \%$ & $3.9 \%$ & $23.2 \%$ & $71.7 \%$ \\
\hline $\begin{array}{l}\text { This activity helped me to identify counseling points for } \\
\text { assistive devices dispensed in the pharmacy. }\end{array}$ & $1.6 \%$ & $0 \%$ & $1.2 \%$ & $26.4 \%$ & $70.9 \%$ \\
\hline $\begin{array}{l}\text { This activity helped me to identify patients who require referral } \\
\text { to physical therapy for assistive device training. }\end{array}$ & $0.9 \%$ & $0.4 \%$ & $5.5 \%$ & $27.2 \%$ & $66.1 \%$ \\
\hline
\end{tabular}

\section{DISCUSSION}

Students' scores on the post-test and responses on the perceptions survey demonstrate the effectiveness of peer teaching in an interprofessional setting. Both PT and pharmacy students' knowledge regarding the use of assistive devices and medications 
affecting safe ambulation improved significantly after participation in the session. This is consistent with the findings of studies investigating the effectiveness of peer to peer teaching occurring between a variety of disciplines and on a variety of topics. 15,21,22 While the overall mean percentage score on the post-assessment was only $69.9 \%$, it is important to note that students completed the post-test one week following activity participation without further class discussion and without reviewing the content. Research has indicated that initial instruction followed by a practice test is better than not having a test at all, and that testing can be more effective than re-study alone for retention. ${ }^{23}$ Given that the students in this IPE session did not have the advantage of immediate testing of knowledge or direction to study the content, their low score might be expected. In addition, scores on the pre or post assessment did not contribute to their course grade, which could have impacted their commitment to retention of the information. Course faculty believe that the statistically significant overall $13 \%$ improvement on the post-test indicates that the students were able to recall information directly from the activity. That low overall score could potentially be raised by providing pre-session content that students would be required to complete. Alternatively, a post-session assignment using cases to apply the newly learned content could facilitate greater retention. Future iterations of this activity could also include an immediate post-test assessment of knowledge, as well as a repeat assessment later to ensure retention of knowledge over time.

It is interesting to note that each profession improved their assessment scores for both their own profession's and the other profession's focused questions. This would seem to indicate that the act of teaching content to their peers facilitated retention both of previously learned and newly learned material. Duran (2017) reviewed the body of literature relevant to the topic of learning by teaching and presented a strong body of work supporting the learning benefits for the teacher both in the area of content knowledge and in ability to teach. ${ }^{24}$ When comparing overall pre and post-test scores of the combined groups, students improved their knowledge more in the area assistive device training than in the area of medications that affect ambulation safety. It is possible that the students were more attentive during the active learning required for assistive device training, both as learners and as instructors. They had an opportunity to practice the newly learned skills, and were checked off on their performance, either of which could have facilitated learning. The benefits of active over passive learning have been described and documented, and when active learning techniques are incorporated, increased learning can occur during educational sessions. ${ }^{25}$ When the groups were examined separately, pharmacy students' knowledge assessment score improved almost three times as much as the PT scores. The PT student scores started higher but did not change as much as the pharmacy students' scores. This could be partly explained by the fact that the PT students do receive some instruction in medications throughout their curriculum but not a focus on medications that impact ambulation, while the pharmacy students do not receive any instruction about assistive device training elsewhere in their curriculum. All students performed poorly on knowledge assessment questions pertaining to indications for PT referral (Appendix A - questions 3 and 5), and while this study does not point to a specific reason for this result, it does indicate a need for increased emphasis on this topic in future offerings of the activity. This content was presented in a more passive format, which could be addressed in future by adding referral discussions to the patient scenarios presented during assistive device training.

Student perceptions of the activity were overwhelmingly positive indicating that the students overall valued the IPE experience. Based on students' perceptions, the peer-to-peer teaching activity provided a feasible and effective platform for both interprofessional education collaborative (IPEC) and course objectives to be met which is consistent with findings from other research. 13,16,21,22,26 Relative to the other items, fewer PT students than pharmacy students agreed/strongly agreed that the activity helped them recognize medications that impair safe ambulation. This perception is consistent with the smaller change score on knowledge of medications. This might be expected as the pharmacy students would have a deeper knowledge of medications and their effects than PT students. Another reason for this difference could be that pharmacy students addressed this learning objective by reviewing a medication chart, which represented dense information learned through a passive process for the PT students. Faculty could consider having pharmacy students develop a more active learning approach to teaching the medication information. In addition, the number of medication classes discussed could be reduced to help facilitate retention by the PT student. The PT students reviewed indications for referral to physical therapy for the pharmacy students, but the pharmacy students did not reciprocate with indications for referral to pharmacy. This would be a useful addition for future iterations of the activity.

One limitation of the current study was the use of a custom designed perception survey rather than a standardized tool to measure the impact of IPE on participating students. While the information gathered was useful in its specificity for the curricular objectives of the disciplines involved, it had not been validated and reliability had not been tested. Future iterations of this event could employ a standard tool such as the Interprofessional Education and Collaborative Practice (IPEC) Competency Self-Assessment survey (Version 3) which measures changes related to an interprofessional experience. ${ }^{27}$ While peer-to-peer teaching has been investigated in the context of interprofessional education, there is limited evidence specifically on reciprocal peer teaching in the interprofessional setting. The opportunity for each discipline to in turn to adopt the role of teacher could foster mutual respect for each other's skills and knowledge and expand understanding of the roles and responsibilities of each discipline in this specific overlapping area of practice. 
This IPE activity presented challenges in terms of the logistics and organization. The disparity in numbers between the pharmacy and PT students meant that the burden of teaching was shared for the pharmacy students but was the sole responsibility for each PT student. Accuracy in content for each group had to be verified prior to the event. The PT students had all successfully completed a competency assessment of clinical skill in assistive device training in a previous semester, which meant that they were not learning new skills, but refreshing old skills. Pharmacy faculty reviewed all of the medication charts created by the pharmacy students for content accuracy and completeness, which placed significant burden on the pharmacy faculty. The event required substantial space and equipment that had to be organized using the university event organizers and required purchase of additional assistive devices to accommodate the large number of groups. Schedules had to be coordinated between departments and required other faculty to adjust schedules. Despite these challenges, faculty involved felt that the benefits made the efforts worthwhile. Students were strongly in favor of the session becoming a regular event (95.3\%) and it has been included in the curricula of both physical therapy and pharmacy practice programs as an annual event.

\section{CONCLUSION}

This activity provided students with the unique interprofessional opportunity to work in small groups and to practice teaching their peers about assistive devices and medications impacting safe ambulation. Students were able to work together to gain a better understanding of their contributions to patient care and to the medical team, as well as improve their understanding of the roles and responsibilities of another healthcare profession. Students became more comfortable with their role, while learning to value the role of another profession, which is an ideal goal for an interprofessional activity. ${ }^{28}$ The added benefit that this type of activity can present is the increase in learning for both the teachers and the learners, and the development of teaching skills in students. The reciprocal nature of this IPE activity could be beneficial in any center where disciplines recognize overlapping areas of academic preparation or professional practice, in addition to the potential for expansion to include discipline specific content of interest to other healthcare professions.

\section{REFERENCES}

1. Buring SM, Bhushan A, Broeseker A, Conway S, Duncan-Hewitt W, Hansen L, Westberg S. Interprofessional education: definitions, student competencies, and guidelines for implementation. Am J Pharm Educ. 2009;73(4):59:1-8.

2. World Health Organization. Framework for Action on Interprofessional Education and Collaborative Practice. Geneva, Switzerland: World Health Organization; 2010. p. 7 http://www.who.int/hrh/resources/framework_action/en/index.html. Accessed July 14th, 2018.

3. Pollard KC, Miers ME. From students to professionals: Results of a longitudinal study of attitudes to pre-qualifying collaborative learning and working in health and social care in the United Kingdom. J Interprof Care. 2008;22(4):399-416. https://doi.org/10.1080/13561820802190483

4. Hammick M, Freeth D, Koppel I, Reeves S, Barr H. A best evidence systematic review of interprofessional education: BEME Guide no. 9. Med Teach. 2007; 29:735-751

5. Reeves S, Perrier L, Goldman J, Freeth D, Zwarenstein M. Interprofessional education: effects on professional practice and healthcare outcomes (update). Cochrane Database Syst Rev 2013, Issue 3. Art. No.: CD002213.

DOI:10.1002/14651858.CD002213.pub3.

6. Accreditation Council for Pharmacy Education. Accreditation standards and key elements for the professional program in pharmacy leading to the doctor of pharmacy degree. https://www.acpe-accredit.org/pdf/Standards2016FINAL.pdf. Standards 2016. Accessed July 2, 2018.

7. Commission on Accreditation in Physical Therapy Education. Standards and Required Elements for Accreditation of Physical Therapy Education Programs. http://www.capteonline.org/AccreditationHandbookl. Accessed July 2, 2018.

8. World Health Organization. Framework for Action on Interprofessional Education and Collaborative Practice. Geneva, Switzerland: World Health Organization; 2010;8. http://www.who.int/hrh/resources/framework_action/en/index.html. Accessed July 14th, 2018.

9. Abu-Rish E, Kim S, Choe L, Current trends in interprofessional education of health sciences students: A literature review. J Interprof Care. 2012;26(6):444-51.

10. Aston et al. Interprofessional Education: A Review and Analysis of Programs From Three Academic Health Centers. Acad Med. 2012 Vol. 87(7)::949-55. doi: 10.1097/ACM.0b013e3182583374.

11. D'eon M. A blueprint for interprofessional learning. J Interprof Care 2005; Supplement 1:49-59.

12. Bridges DR, Davidson RA, Soule Odegard P, Maki IV, Tomkowiak J. Interprofessional collaboration: three best practice models of interprofessional education. Med Educ Online 2011;16: 6035 - DOI: 10.3402/meo.v16i0.6035. 
13. Burgess $A$ and Deborah McGregor $D$. Peer teacher training for health professional students: a systematic review of formal programs. BMC Med Educ. 2018;18:263. https://doi.org/10.1186/s12909-018-1356-2. [PMID: 30442139]

14. Lehrer MD, Murray S, Benzar R, et al. Peer-led problem-based learning in interprofessional education of health professions students. Med Educ. 2015;20(1): 28851. [PMID: 26344391]

15. Dunleavy K, Galen S, Reid K, Dhar PJ, DiZazzo-Miller R. Impact of interprofessional peer teaching on physical and occupational therapy student's professional role identity. J Interprof Educ Pract. 2017; 6: 1-5Report, (14). Washington, D.C.: U.S. Department of Education, National Institute on Disability and Rehabilitation Research. 2000.

16. Sadowski CA, Li JC, Pasay D, Jones CA. Interprofessional peer teaching of pharmacy and physical therapy students. Am J Pharm Educ. 2015; 79(10): Article 155. [OPMID: 26889067]

17. Shields RK, Pizzimenti MA, Dudley-Javoroski S, Schwinn DA. Fostering interprofessional teamwork in an academic medical center: Near-peer education for students during gross medical anatomy. Anat Sci Educ. 2015;8(4):331-7. [PMID: 24888728]

18. Lipton HL, Lai CJ, Cutler TW, Smith AR, Stebbins MR. Peer-to-peer interprofessional health policy education for Medicare Part D. Am J Pharm Educ. 2010;74(6):102. [PMID: 21045944]

19. Kaye HS, Kang T, and LaPlante MP. Mobility Device Use in the United States. Disability Statistics Report, (14). Washington, D.C.: U.S. Department of Education, National Institute on Disability and Rehabilitation Research. 2000.

20. De Jong MR, Van der Elst M, Hartholt KA. Drug-related falls in older patients: implicated drugs, consequences, and possible prevention strategies. Ther Adv Drug Saf. 2013;4(4):147-54. [PMID: 25114778]

21. Core competencies for interprofessional collaborative practice: 2016 update. Washington, DC: Interprofessional Education Collaborative. https://ipecollaborative.org/uploads/IPEC-2016-Updated-Core-Competencies-Report_final_release_.PDF. Accessed July 2, 2018

22. Bain $P$, Wareing $A$, Henderson I. A review of peer-assisted learning to deliver interprofessional supplementary image interpretation skills. Radiography. 2017;23:S64-9. [PMID: 28780955]

23. Simon LE, Eve EJ, Dolce MC, Allareddy V, Nalliah RP. Physician Assistant Student Perceptions of an Interprofessional, Peer-to-Peer Oral Health Curriculum Led by Dental Students. J Physician Assist Educ. 2017;28(4):210-3. [PMID: 29189652]

24. Rawson KA, Vaughn KE, Carpenter SK. Does the benefit of testing depend on lag, and if so, why? Evaluating the elaborative retrieval hypothesis. Mem \& Cognit. 2015;43(4):619-33.

25. Duran D. Learning-by-teaching. Evidence and implications as a pedagogical mechanism. Innov Educ Teach Int. 2017;54(5):476-84.

26. Wolff M, Wagner MJ, Poznanski S, Schiller J, Santen S. Not another boring lecture: engaging learners with active learning techniques. J Emerg Med. 2015;48(1):85-93.https://doi.org/10.1016/j.jemermed.2014.09.010

27. Tunney N, Chesson MM, Kamp F, Mattingly JR, Ryan GJ. Activities designed to simultaneously meet discipline-specific course objectives and interprofessional education competencies. J Interprof Educ Pract. 2018;10(1):24-9.

28. Lockeman KS, Dow AW, Randell AL (2018) Validity Evidence and Use of the IPEC Competency Self-Assessment, Version 3. Presented at the American Educational Research Association (AERA) 2018 Meeting in New York, NY on April 15, 2018

29. Clark, P. What would a theory of interprofessional education look like? Some suggestions for developing a theoretical framework for teamwork training. J Interprof Care. 2006; 20: 577-589. [PMID: 17095437]

\begin{tabular}{|c|c|}
\hline Question & Answer Choices (correct answer marked in bold) \\
\hline $\begin{array}{l}\text { 1. When instructing the customer in the transition from sit to } \\
\text { stand you emphasize the need to lean forward before } \\
\text { pushing up to stand. }\end{array}$ & $\begin{array}{ll}\text { a. } & \text { True } \\
\text { b. } & \text { False }\end{array}$ \\
\hline 2. Proper fit of axillary crutches is achieved when: & $\begin{array}{l}\text { a. The top of the axillary pad is at least } 2 \text { finger } \\
\text { breadths from the axilla } \\
\text { b. The patient's elbows are approximately in } 60 \\
\text { degrees of flexion when the crutch tips are in } \\
\text { line with the body } \\
\text { c. The wrist is in full extension allowing good } \\
\text { weight bearing through the arms with little } \\
\text { muscular effort } \\
\text { d. None of the above are correct }\end{array}$ \\
\hline $\begin{array}{l}\text { 3. Your customer is a healthy } 58 \text { year-old with a history of } \\
\text { arthritis and recent increase in left hip pain of from } 2 \text { to } 5 \text { on a } \\
0-10 \text { pain scale. Pain increases with ambulation. He asks }\end{array}$ & $\begin{array}{l}\text { a. Sell him a straight cane } \\
\text { b. Sell him a single crutch } \\
\text { c. Sell him a rolling walker }\end{array}$ \\
\hline
\end{tabular}




\begin{tabular}{|c|c|c|}
\hline & $\begin{array}{l}\text { you for advice on selection of an assistive device. The most } \\
\text { appropriate action for you to take would be to: }\end{array}$ & d. Refer him to Physical Therapy \\
\hline 4. & $\begin{array}{l}\text { Your customer is recovering from a CVA with right } \\
\text { hemiplegia and has just been discharged from the hospital. } \\
\text { He brings a prescription for a cane. You instruct him to } \\
\text { ambulate with the cane in which hand? }\end{array}$ & $\begin{array}{l}\text { a. The right } \\
\text { b. The left } \\
\text { c. Either side is acceptable }\end{array}$ \\
\hline 5. & $\begin{array}{l}\text { Miss Jones is an obese } 25 \text { year-old female recovering from a } \\
\text { fractured left tibia/fibula. She has exercise-induced asthma } \\
\text { and ulcerative colitis. She uses a steroid inhaler to manage } \\
\text { her asthma. She is cleared for toe touch weight-bearing on } \\
\text { the injured leg. She is expected to progress to full weight- } \\
\text { bearing in } 6 \text { weeks. Strength in BUE's and RLE is normal } \\
\text { and her balance is fair but she is unable to stand on one leg } \\
\text { without support. Which of the following assistive devices } \\
\text { would be most appropriate for Miss Black to begin assistive } \\
\text { device training with? }\end{array}$ & $\begin{array}{l}\text { a. Standard walker } \\
\text { b. Axillary crutches } \\
\text { c. Refer to Physical Therapy } \\
\text { d. Rolling walker }\end{array}$ \\
\hline 6. & $\begin{array}{l}\text { Your customer is a } 79 \text { year-old man recently discharged from } \\
\text { the hospital after receiving treatment for pneumonia. He } \\
\text { feels a little weak and tires easily. He asks you to } \\
\text { recommend an assistive device for pneumonia. Which of the } \\
\text { following assistive devices would be most appropriate? }\end{array}$ & $\begin{array}{l}\text { a. Rolling walker } \\
\text { b. Straight cane } \\
\text { c. Quad cane } \\
\text { d. Crutches }\end{array}$ \\
\hline 7. & $\begin{array}{l}\text { You are fitting a customer for a rolling walker. Correct fit } \\
\text { would include: }\end{array}$ & $\begin{array}{l}\text { a. The top of the hand grip is level with the hip } \\
\text { b. The patient's elbows are approximately in } \\
\text { 20-30 degrees of flexion when the walker is } \\
\text { placed in front of her } \\
\text { c. The shoulders are elevated to allow for good } \\
\text { push-up during gait } \\
\text { d. All of the above are correct }\end{array}$ \\
\hline 8. & $\begin{array}{l}\text { Olivia is a } 30 \text { year-old female with cerebral palsy. She has } \\
\text { been using a rolling walker for several years, but needs a } \\
\text { new one. She presents with weakness in both legs but more } \\
\text { significantly in the right leg. Following sale of the walker, you } \\
\text { are reviewing walker ambulation with her and demonstrate } \\
\text { which of the following sequences? }\end{array}$ & $\begin{array}{ll}\text { a. } & \text { Walker, right leg, left leg } \\
\text { b. } & \text { Right leg, left leg, walker } \\
\text { c. } & \text { Walker, left leg, right leg } \\
\text { d. } & \text { Left leg, right leg, walker }\end{array}$ \\
\hline 9. & $\begin{array}{l}\text { All of the following are adverse effects of medications that } \\
\text { can cause impairment in gait or unsafe ambulation EXCEPT: }\end{array}$ & $\begin{array}{ll}\text { a. } & \text { Drowsiness } \\
\text { b. Orthostatic hypotension } \\
\text { c. Vision disturbance } \\
\text { d. Gastrointestinal irritation }\end{array}$ \\
\hline 10. & $\begin{array}{l}\text { When a benzodiazepine is prescribed for a patient, what } \\
\text { possible adverse event may increase the patient's risk of } \\
\text { unsafe ambulation? }\end{array}$ & $\begin{array}{ll}\text { a. } & \text { Drowsiness } \\
\text { b. Dizziness } \\
\text { c. Orthostatic hypotension } \\
\text { d. Both A and B } \\
\end{array}$ \\
\hline 11. & $\begin{array}{l}\text { Your customer is a } 70 \text { year-old male with osteoporosis } \\
\text { requiring the use of a walker who presents to the pharmacy } \\
\text { with complaints of insomnia. The patient asks you if it is safe } \\
\text { for him to take diphenhydramine to help with his insomnia. } \\
\text { Which of the following is an adverse effect of } \\
\text { diphenhydramine that could worsen this patient's gait? }\end{array}$ & $\begin{array}{ll}\text { a. } & \text { Drowsiness } \\
\text { b. Visual disturbances } \\
\text { c. Dizziness } \\
\text { d. Orthostatic hypotension }\end{array}$ \\
\hline 12. & $\begin{array}{l}\text { Mrs. Wilson is a } 55 \text { year-old female recovering from a } \\
\text { fractured left tibia/fibula. She has hypertension, gastric reflux } \\
\text { disease, and chronic back pain. She is cleared for toe touch } \\
\text { weight-bearing on the injured leg. She is expected to } \\
\text { progress to full weight-bearing in } 6 \text { weeks. She visits your } \\
\text { clinic for evaluation and assistive device training. During the } \\
\text { visit, the patient complains of dizziness upon standing. You }\end{array}$ & $\begin{array}{ll}\text { a. Morphine } \\
\text { b. Hydrochlorothiazide } \\
\text { c. Omeprazole } \\
\text { d. Baclofen }\end{array}$ \\
\hline
\end{tabular}




\begin{tabular}{|l|l|}
\hline $\begin{array}{l}\text { review her medication list because you are concerned that } \\
\text { one of her home medications could be contributing to unsafe } \\
\text { ambulation. All of the following medications could contribute }\end{array}$ & \\
to Mrs. Wilson's dizziness upon standing EXCEPT: & \\
\hline $\begin{array}{l}\text { 13. Which of the following medication classes is associated with } \\
\text { visual disturbances that could impair gait? }\end{array}$ & $\begin{array}{l}\text { a. Benzodiazepines } \\
\text { b. Eye drops }\end{array}$ \\
\hline c. Antipsychotics \\
14. Narcotics can cause orthostatic hypotension resulting in & $\begin{array}{l}\text { a. True } \\
\text { unsafe ambulation. }\end{array}$ \\
& b. False \\
\hline 15. Which of the following medications and side effect that can & a. Alcohol - orthostatic hypotension \\
cause unsafe ambulation is incorrectly paired? & b. Haloperidol - Drowsiness \\
& c. Lorazepam - Dizziness \\
& d. Gabapentin - Drowsiness \\
\hline
\end{tabular}

